\title{
Análisis semiótico de la fotografía de perfil de jóvenes en Tuenti
}

\author{
Max RÖMER PIERETTI \\ Universidad Camilo José Cela \\ mwalter@ucjc.edu \\ Emeterio DíEz PuERTAS \\ Universidad Camilo José Cela \\ ediez@ucjc.edu \\ María del Mar PeRelló Rosselló \\ Universidad Camilo José Cela \\ mmperello@ucjc.edu
}

Recibido: $16 / 07 / 2012$

Aceptado: 08/10/2012

\section{Resumen}

El espacio de interacción entre los jóvenes, por ser un ámbito cercano, con el que han crecido, es la web 2.0. Es nativo el uso, la capacidad de asimilación y socialización, que hacen los jóvenes de este entorno. Para comprender las relaciones de signos que establecen y el por qué, plantemos un estudio de los perfiles fotográficos desde el análisis de las funcionalidades del signo de C.S.Peirce. Esta investigación se lleva a cabo mediante el estudio de las fotografías de diez adolescentes, contrastadas con entrevistas en profundidad e interpretando los datos a partir de una matriz desarrollada por los investigadores Römer y Díez. Este trabajo nos permite seguir profundizando en la línea de investigación del estudio semiótico del signo virtual en las redes sociales.

Palabras clave: Redes sociales, adolescentes, fotografía, semiótica.

\section{Semiotic analysis of Tuenti's young photographic profile}

\begin{abstract}
The space of interaction among young people, being close range, with which they have grown, it is web 2.0. It is native to the use, ability to assimilate and socialization, young people do in this environment. To understand the relationship of signs down and why, plant a photographic study of the profiles from the analysis of the features CSPeirce mark. This research was conducted by studying the photographs of ten teenagers, contrasted with in-depth interviews and interpreting data from a matrix developed by researchers Römer and Díez. This work allows us to further deepen the research of virtual sign semiotic study of social networks.
\end{abstract}

Keywords: Social Networks, teenagers, photography, semiotics

\section{Referencia normalizada}

RÖMER PIERETTI, Max; DÍEZ PUERTAS, Emeterio; y PERELLÓ ROSELLÓ, María del Mar (2012): “Análisis semiótico de la fotografía de perfil de jóvenes en Tuenti”. Estudios sobre el mensaje periodístico. Vol. 18, núm. especial noviembre, págs.: 811-818. Madrid, Servicio de Publicaciones de la Universidad Complutense.

Sumario: 1. Introducción. 2. Mirada Semiótica. 3. Metodología. 4. Analizando a los adolescentes y su relación semiótica con las redes sociales 5. Legisígnico-simbólico-dicente. 6. Conclusiones. 7. Referencias bibliográficas. 


\section{Introducción}

Hoy en día, las redes sociales son práctica diaria de buena parte de la población; el entorno de nuestras relaciones ha cambiado y, ahora, vivimos en red. Entre todas las redes sociales, "Tuenti ha sacado partida a su apuesta por la población más joven, la mayoría de ellos 'nativos digitales' que han crecido familiarizados con todas las posibilidades que el mundo online puede aportar a la vida real" (Fernández, 2009:41).

En este artículo queremos mostrar, a través del perfil fotográfico de la red social Tuenti, cómo los jóvenes utilizan esta red social a sabiendas de su condición de EMEREC (emisor-medio-receptor), función que establece las bases del uso de las redes sociales enunciada por Castells (2009). Concluimos que los adolescentes se mueven dentro de la función 'legisígnica-simbólica-dicente', donde su imagen de perfil (representamen) les remplaza para generar una etiqueta particular en sus contactos (semiosis) de la red (interpretantes).

Las fotografías de los perfiles serán analizadas con una matriz semiótica desarrollada sobre los postulados de Charles S. Peirce. Las relaciones de primariedad, secundidad y terceridad que se encuentran en estos textos fotográficos de la muestra en su contexto de perfil de red social abarcan alguna de las diez relaciones propuestas por la funcionalidad peirciana y, además, nos permite trasladar este modo de analizar semióticamente a formas no estudiadas originalmente por Peirce como lo es el mundo de la web 2.0. Algunas investigaciones se han hecho en este sentido. Autores postpeircianos como Vidales (2009), Warschauer y Grimes (2007) y Wei-Ching Huang, A. y Tyng-Ruey, C. (2009) han explorado la relación de la funcionalidad del signo peirciano en Internet. Esto da pie a que nuestro estudio empírico de campo en un ámbito en el que queremos ir al plano simbólico del signo del perfil de un usuario, sea una relación inacabada y digna de exploración, con la posibilidad de permear hacia investigaciones sobre la interacción de los individuos que interactúan en la red que van más allá de las propias de la socialización cara a cara.

\section{Mirada semiótica}

De las diez relaciones del signo peirciano que podrían encontrarse en los perfiles de los adolescentes estudiados no solamente a través del análisis de la fotografía de perfil sino de la narrativa que se da con en la sumatoria de imágenes que cada usuario en su condición de EMEREC (Castells, 2009 en Römer y Díez, 2011) tiene en su perfil, el estudio realizado contempla aspectos que no fueron tratados por Peirce. El concepto de rol directo que proponemos en la matriz obedece a la dicencia peirciana, es decir, lo que el EMEREC pretende con su fotografía, lo que en un proceso de comunicación sería evidente, pero indispensable para la comprensión del fenómeno de comunicación. Las últimas dos casillas, funcionalidad semiótica y relación de narratividad semiótica, son directamente vinculadas a la funcionalidad del signo peirciano y; la hipermediación que asociamos a la funcionalidad semiótica, si bien está tomada de la relación mediática de Peirce, al estar construida desde la propia red, constituye un avance en lo que a los estudios sobre la funcionalidad del signo peirciano, que se traduce en la relación del signo expresado a través de las redes sociales y de sus posibilidades de interacción con otros sujetos con el texto y contexto propuesto por un EMEREC. 
En el ámbito de la semiótica hay que destacar que Peirce definió diez relaciones del signo o funcionalidades así: Primariedad: 1. Cualisigno-icónico-remático; Secundidad: 2. Sinsigno-icónico-remático, 3. Sinsigno-indicial-remático, 4. Sinsigno-indicial-dicencia; Terceridad: 5. Legisigno-incónico-remático, 6. Legisigno-indicial-remático, 7. Legisigno-indicial-dicente, 8. Legisigno-simbólicoremático, 9. Legisigno-simbólico-dicente, 10. Legisigno-simbólico-argumental (Peirce, §§ 2.254-63, 8.341 en Nöth, 1995: 45).

Así, tratamos de encontrar la mayor cantidad de una funcionalidad para adoptar conclusiones que nos permitan desde la semiótica que los perfiles de Tuenti, en su contexto de red social, al tener una descripción propia del propietario del perfil, así como un conjunto de relaciones que el EMEREC quiere destacar, para corroborar la hipótesis: "Los sujetos que usan la red social Tuenti, sabiendo de su condición de Emerec, plantean sus comunicaciones -amparadas en la fotografía- como una funcionalidad del tipo "legisígnica-simbólica-dicente"”. En este sentido, los signos icónicos presentes en las fotografías relacionan a los adolescentes con su rol directo de sexo, edad, raza y amistad, a la vez que con dos elementos que consideramos instituciones: amor y cuerpo. La amistad se representa semióticamente con la puesta en escena de la proximidad y el empleo de símbolos. El cuerpo, por su parte, con los signos de caracterización de la edad (Díez y Römer, 2011a).

El análisis de estos mensajes en forma de fotografías se ha efectuado a partir de la foto del perfil y de un esquema clasificatorio de etiquetas en redes sociales (Díez y Römer 2011a). Sostuvimos que la identidad fotográfica en red se construye subiendo fotos en las que el usuario ha establecido una serie de elecciones de signo (escala de plano, textura, punto de vista, color, etc.) en virtud de las cuales crea una serie de etiquetas faciales (de combinaciones de signos) que remiten a una etiqueta social. Parafraseando a Peirce una etiqueta facial es un signo fotográfico que existe para alguien, por algo y en algún aspecto o disposición con el fin de construir un rol. El usuario se muestra "representando" determinado papel. El representamen es una actuación para el interpretante. Las tres etiquetas sociales más repetidas en las redes, según este trabajo, están relacionadas con tres instituciones: el Cuerpo, el Amor y el Ocio. Dentro de estas instituciones, el usuario quiere asumir el rol de S.E.R. (sexo, edad, raza) Bello, AMIGO Amoroso y Ocioso AVENTURERO. Por esta razón, en la matriz que usamos en este estudio excluimos los aspectos relativos a las etiquetas sociales y faciales.

\section{Metodología}

Dentro de esta nueva realidad, el grupo de Investigación Young.net de la Universidad Camilo José Cela tiene como propósito el desarrollo de un estudio de los recursos y técnicas específicas de enmascaramiento orientadas a afianzar relaciones íntimas con menores a través de las redes sociales. Sobre esta base, se han definido una serie de objetivos que, en el ámbito comunicativo y semiótico, incluye el estudio de los perfiles de los usuarios adolescentes en las redes sociales. Previamente, el grupo de investigación ha desarrollado una serie de avances metodológicos que comprenden la creación de una matriz que se compone de tres grandes unidades de estudio: el 
análisis semiótico (Römer et al., 2012a y 2012b), la relación entre los perfiles faciales y sociales en las fotografías (Díez et al., 2011a) y el estudio del ámbito simbólico, especialmente a través de los vídeos, en las redes sociales (Díez et al., 2011b).

En consecuencia, la propuesta metodológica es aplicar el paradigma de relaciones funcionales de Peirce, así como relacionar estas funcionalidades con los elementos descritos en la matriz de análisis expuesta como figura $\mathrm{N}^{\mathrm{o}} 1$. Así:

\begin{tabular}{|l|l|l|l|}
\hline Institución & Rol directo (dicencia) & Funcionalidad semiótica/hipermediación & Relación de narratividad semiótica \\
\hline
\end{tabular}

Figura $\mathrm{N}^{\mathrm{o}}$ 1: Matriz de análisis semiótico para el texto fotográfico.

\section{Analizando a los adolescentes y su relación semiótica con las redes sociales}

La adolescencia se desarrolla hoy en un contexto tecnológico de relaciones personales. Internet ha cambiado la vida de los jóvenes en el sentido de que hacen las cosas con mayor economía de tiempo, globalizando su actividad y para ellos, se han difuminado las fronteras entre el juego y el estudio, el ocio y el trabajo, lo público y lo privado, lo escrito y lo audiovisual, lo adulto y lo joven, la comunidad de amigos y la de marca (Rubio, 2007; Bernete, 2010; Núñez-Gómez y García-Guardia, 2012).

El aumento de los "nativos digitales" explica que el uso de Internet no pare de crecer. El porcentaje de jóvenes que utilizan Internet ha pasado de un $51 \%$ en 2003 a un $70 \%$ en 2007 (Rubio, 2007) y a un 96,3\% en el 2010 (INE, 2010). La cantidad y frecuencia de uso es mucho mayor en comparación con las generaciones precedentes. Para ellos la red es un medio que les facilita: diversión (79,7\%), productos culturales (el $85 \%$ descarga de filmes y música; el 53,4\% busca viajes y entradas), formación (el $67,3 \%$, aprendizaje; el $89,6 \%$, información), oportunidades de trabajo $(58,5 \%)$ y, como vamos a ver, relaciones sociales ( $80 \%$ relacionarse; $30 \%$ contactar) (INE, 2010).

La búsqueda de relaciones explica que, según el estudio Generación 2.0 2011, entre el $80 \%$ y el $90 \%$ de los adolescentes, en edad escolar, emplee las redes sociales. En la mayoría de los casos, el uso es bastante reciente y la mayoría se enteraron de su por medio de una amistad, sobre todo, en el caso Tuenti, que es la red que prefiere el 91\% de los adolescentes españoles (Sánchez et al., 2011). Según el ranking sobre tráfico de webs en España realizado por Alexa (2012), Tuenti cuenta con alrededor de catorce millones de usuarios registrados. Dice Laura, una de las adolescentes a la que entrevistamos: "La gente lo tenía ya, de antes [...] ‘PPues me voy a hacer Tuenti!”

El número de contactos que tienen los usuarios adolescentes es amplio, un $65 \%$ tiene más de 100 amigos. La mayoría de éstos forman parte de las redes sociales tradicionales, (familia, los amigos y conocidos). En nuestra muestra, el 90\% de los adolescentes señala su colegio en el apartado Redes, si bien, también algunos de los encuestados dicen que incluyen a personas desconocidas como contactos. Estas práctica no suele ser habitual; las encuestas indican que el 54\% de los adolescentes preserva su privacidad y solo un $7 \%$ ha incluido o se ha citado con personas desconocidas (Sánchez et al. 2011). No obstante, un 57\% admitiría tener una cita personal con una persona conocida a través de Internet y, de aquellos que ya la han tenido, un $72 \%$ sostiene que fue una experiencia positiva (Sánchez et al., 2010). 
Las actividades en red más habituales son: "Mandar mensajes privados" $(42,5 \%)$, "Actualizar mi perfil" (33\%), "Informarme por cosas que me interesan" (24\%), "Cotillear" (22\%), "Jugar en la red" (11\%) y, sobre todo, "Compartir o subir fotos" (algo más del 50\%) y "Comentar las fotos de mis amigos" (48\%) (Sánchez et al., 2010). La actividad relacionada con la proyección de la propia imagen a través del texto fotográfico es una parte fundamental de la interacción dentro de la red.

Para corroborar esta hipótesis se ha tomado como muestra parte de los resultados obtenidos en el estudio que desarrolla el grupo de investigación Young.net de la UCJC. La muestra seleccionada por el grupo de investigación atendía a los tres factores que siguen: el sexo (chico/chica); la edad (púberes/adolescentes), para abarcar la horquilla de los 10 a los 19 años, la adolescencia completa; y la frecuencia de uso de las redes sociales (poco frecuente/intermedio/intenso). A raíz de estas categorías se podían obtener 12 tipos de discursos. Por ello, el grupo de investigación decidió llevar a cabo 24 entrevistas en profundidad, realizando dos por cada tipo de discurso. Asimismo, se completó la recogida de información con ocho grupos de discusión (de ocho integrantes cada uno) formados a partir de la frecuencia de uso de las redes sociales. Así pues, se llevó a cabo el análisis de 88 perfiles, entre las entrevistas y los grupos de discusión.

De ese número total de adolescentes entrevistados, diez permitieron que realizásemos un seguimiento de su página durante 7 días: del 22 al 28 de mayo de 2012. Ellos constituyen nuestra muestra de análisis fotográfico. Residen en la Comunidad de Madrid y en un $60 \%$ de los casos son amigos entre ellos. Su edad oscila entre los 13 y los 15 años, pero en la red declaran tener entre 14 y 19 años (Tuenti solo admite usuarios mayores de 14 años). La mitad de ellos mienten sobre su edad (un joven se sube 6 años, dice tener 19 años y tiene 13). Este dato, unido a que un $20 \%$ oculta su identidad o mienten sobre el lugar en que estudian, plantea dudas acerca de lo afirmado por la propia red Tuenti cuando se asevera que los usuarios se registran con su verdadero nombre sin que medien falsas identidades (Sabaté, 2008).

Los jóvenes de nuestra muestra se dieron de alta en Tuenti entre noviembre de 2008 y noviembre de 2011. El usuario más veterano lleva registrado más de tres años y el más novel, seis meses. Por lo tanto, la media de uso de la red es de 16 meses.

\begin{tabular}{|l|l|l|}
\hline USO DE SU CUENTA TUENTI & Media & Sobrepasa la media \\
\hline Recomendación de sitios & 1.4 & \\
\hline Recomendación de redes & 1 & \\
\hline $\begin{array}{l}\text { Recomendación de páginas (relacionadas con el ocio y la } \\
\text { diversión }\end{array}$ & 39 & \\
\hline Publicaciones en el Espacio personal & 12.5 & 56 \\
\hline Número de amigos & 179 & 252 \\
\hline Cambio de fotografía de perfil & $1.5 /$ semana & \\
\hline Fotografías & 800 & \\
\hline Álbumes de fotografías & 3 & 11 \\
\hline
\end{tabular}

Figura $\mathrm{N}^{\circ}$ 2: Resumen de interacciones de la muestra estudiada

Sabemos que la mayoría de los adolescentes utilizan varias redes sociales al mismo tiempo. En cada una encuentran pros y contras y, por ende las utilizan con fines distintos. Usan Facebook, pero dicen que es para adultos. Usan Twitter, pero señalan 
que las fotos no funcionan. Tuenti es su red preferida cuando quieren interaccionar en público, para mostrar lo que está pasando, y consideran que es ideal para subir fotos.

En nuestra muestra, una parte fundamental de la actividad comunicativa se realiza a través de mensajes en forma de fotografias. Casi todos los entrevistados manifestaron que para ellos esta actividad es muy relevante. En la mayoría de los casos, porque suben muchas fotos, se preocupan en seleccionarlas y son públicas. Laura, dice: "Me gusta fotografiarme a mí misma. [...] La retoco [...] para que quede mejor". Alba, jugadora de baloncesto, afirma: "Tengo un montón de fotos desde que me compré la réflex. [...] Luego las mejores se las pasó a los jugadores y muchos se la ponen en el perfil. Eso me encanta". Incluso aquellos adolescentes que no suben muchas fotos son conscientes de que su "imagen" está circulando en la red, pues aparecen en fotos que suben los amigos. Un joven llamado Alex comenta: "Tengo bastantes fotos. La verdad [...] no tengo cámara... Pero la gente hace fotos, ¿no? Y sales tú y te etiquetan [...]”.

También suele ocurrir que esa importancia dada a la foto, se traduzca en todo lo contrario: se suben pocas, muy seleccionadas y nunca son públicas. Raquel, por ejemplo, no suele subir fotos o sube las justas. Nina, por su parte, tuvo que denunciar una vez una foto que no le gustó porque salía dormida, pero parecía drogada. La subió una compañera del colegio con la que se llevaba mal y tuvo que denunciarla y con el requerimiento la quitó. También Alex conoce un caso de intromisión en la propia imagen a través de una foto. "Salíamos todos en grupo y le taparon la cara con un emoticono. Denunció la foto y la quitaron."

\section{Legisígnico-simbólico-dicente}

La funcionalidad del signo que opera en las fotografías de los perfiles de Tuenti de la muestra analizada son legisígnico-simbólico-dicentes. Esta condición se da en casi todos los casos analizados, a excepción de un par de casos de chicas que solo son legisígnico-simbólico-remático, por mostrar solamente una parte del cuerpo. En este último caso la funcionalidad del signo dice: Soy sexy, pero no quiero que sepas quién soy. Al alejarse de lo simbólico se acerca el signo a lo remático lo que significa que el interpretante tiene dudas sobre el representamen.

Lo mismo ocurre con los pictogramas porque a pesar de usar un nombre masculino, la relación icónica de sexo no se puede establecer con una máscara de este tipo, no sabemos si detrás del pictograma se esconde un chico o una chica.

Al ser la mayoría de las relaciones de funcionalidad legisígnicas-simbólicasdicentes podemos saber que el ámbito de la argumentación solo se produce cuando las fotografías dan pie para que dentro del contexto de los perfiles de Tuenti, la relación de EMEREC interactúe con otros EMEREC. Es allí donde, sí y solo sí, se presenta una relación de comprensión del signo por su relación simbólica, se puede establecer el ámbito de la argumentación como el silogismo que pretende. Esto se da en 7 de los diez casos, adoptando el icono una funcionalidad que lo supera con creces, toda vez que el icono supera la secundidad y pasa a la terceridad. Va más allá del mero hecho del representamen y adopta una condición muy diáfana para su condición de interpretante. 


\section{Conclusiones}

La forma del signo y su funcionalidad obedecen a una necesidad, un lenguaje y un contexto específico en el sentido de que ese signo construye, y como un código (legisigno) para que alguien sustituya al usuario por su foto (discencia) con el fin de que se le vea bajo una determinada etiqueta social (símbolo), y en los casos en los que no se produce esta funcionalidad, la duda que produce el no reconocer al usuario, genera una aproximación del signo desde el ámbito remático, lo que se solventa creemos y nos aventuramos a hipotetizar, con el contexto general del perfil, las publicaciones de ese sujeto y, porqué no decirlo, de sus propios círculos de amistad.

Por otro lado, como hallazgo colateral, podemos corroborar que el uso de la red social Tuenti tiene como propósito en sus usuarios el intercambiar sus imágenes como propias, como una terceridad indispensable para el manejo del sexo, edad y raza, así como para la creación de perfiles de identidad que por su relación semiótica den tanto de sí, como una relación social de persona a persona.

\section{Referencias bibliográficas}

ALEXA, THE WEB INFORMATION COMPANY (2012): Top sites in Spain. Disponible en: http://www.alexa.com/topsites/countries/ES.

BERNETE GARCÍA, Francisco (2010): "Usos de las TIC. Relaciones sociales y cambios de las y los jóvenes“", en Revistas de Estudios de la Juventud: nº 88, pp. 97114. Madrid, Injuve.

CASTELLS, Manuel (2009): Comunicación y Poder. Madrid, Alianza Editorial.

DÍEZ, Emeterio y RÖMER, Max. (2011a) "Material fotográfico en las redes sociales: cómo las etiquetas faciales crean etiquetas sociales", en: SIERRA, Javier (Coord.): Retos y oportunidades de la comunicación multimedia en la era 2.0. Madrid, Fragua.

DÍEZ, Emeterio y RÖMER, Max (2011b): "Sociedad del Riesgo-Sociedad Red. El Arturo simbólico en las redes sociales del movimiento «Marea Verde» “, en Jornada Científica UCJC- SEP: De las pantallas al bolsillo [En Publicación]. Madrid, Universidad Camilo José Cela.

EFE (2012): Tuenti se renueva e internacionaliza. En: 20minutos.es. Disponible en: http://www.20minutos.es/noticia/1536382/0/tuenti/renovacion/internacionalizacion

FERNÁNDEZ, Juan (2009): “Tuenti: El innovador milagro de la red social made in Spain“, en MK: Marketing + ventas, $n^{\circ} 250$. Madrid.

INSTITUTO NACIONAL DE ESTADÍSTICA (INE, 2010): "Perfil sociodemográfico de los internautas". En: Análisis de datos INE 2010. Madrid, INE. http://www.osimga.org/export/sites/osimga/gl/documentos/d/20110905_perfil_sociodemo_2010.pdf

NÖTH, Winfred (1995): Handbook of Semiotics. Indiana, Indiana Press University.

NÚÑEZ-GÓMEZ, Patricia y GARCÍA-GUARDIA, María (2012): “Tendencias de las relaciones sociales e interpersonales de los nativos digitales y jóvenes en la 
web 2.0", en Revista Latina de Comunicación Social, n 67. La Laguna (Tenerife), Universidad de La Laguna.

RÖMER, Max. (2010): "En el reality show de la web 2.0. Una aproximación metodológica desde la semiótica“, en Alfabetización Mediática y Culturas Digitales. Sevilla, Gabinete de Comunicación y Educación.

RÖMER, Max y DÍEZ, Emeterio (2012a): 'Young net', una aproximación al mundo social de los jóvenes en Red, en VV.AA.: Las sociedades en red: sociabilidad y mediación tecnológica, Vol. 1. Barranquilla, Colombia, Universidad del Norte Colombia Digital.

RÖMER, Max y DÍEZ, Emeterio (2012b): “Análisis fotográfico de perfiles en las hipermediaciones sociales", en XIV Congreso de Semiótica, [En publicación]. Cuenca, Asociación Española de Semiótica.

RUBIO GIL, Ángeles. (2007): Adolescentes y jóvenes en la red: factores de oportunidad. Instituto de la Juventud de España, Madrid.

SABATÉ, Jordi (2008): Entrevista con Zaryn Dentzel, presidente de Tuenti: El éxito de Tuenti radica en la garantía de privacidad que ofrece. Disponible en: http://www.consumer.es/web/es/tecnologia/internet/2008/04/10/175859.php Consultado el 11 de julio de 2012

SÁNCHEZ, Adolfo y ÁLVARO, Adolfo (2011): Generación 2.0 2011. Hábitos y usos de las redes sociales en los adolescentes de España y América Latina. Madrid, Universidad Camilo José Cela. Disponible en: http://www.slideshare.net/ucjc/generacin-20-2011-hbitos-de-usos-de-las-redes-sociales-en-los-adolescentes-de-espaa-yamrica-latina

SÁNCHEZ, Adolfo y POVEDA, María. (2010): Informe Generación 2.0 2010: Hábitos de los adolescentes en el uso de las redes sociales. Estudio comparativo entre Comunidades Autónomas. Madrid, Universidad Camilo José Cela, Madrid. Disponible en: http://www.slideshare.net/ucjc/generacin-20-hbitos-de-los-ad.

SÁNCHÉZ, María, PRENDES, María y SERRANO, José. (2011): "Modelos de interacción de los adolescentes en contextos presenciales y virtuales", en Edutec-e: $n^{\circ}$ 35, pp. 1-14. Murcia.

VIDALES, Carlos (2009): "Semiótica, Cultura y Comunicación. Las bases teóricas de algunas confusiones conceptuales éntrela semiótica y los estudios de la comunicación“, en Razón y Palabra. Febrero, n 66. México.

WARSCHAUER, Mark y GRIMES, Douglas (2007): “Audience, authorship and artifact: the emergent semiotics of web 2.0", en Annual Review of Applied Linguistics. Marzo, vol. 27. Cambridge.

WEI-CHING HUANG, Andrea, TYNG-RUEY, Chuang (2009): "Social tagging, online communication, and Peircean semiotics: a conceptual framework", en Journal of Information Science. Junio, Vol. 35. Amsterdam. 


\section{Max RÖMER PIERETTI}

Profesor doctor del Departamento de Periodismo de la Facultad de Ciencias de la Comunicación. Universidad Camilo José Cela

\section{Emeterio DÍEZ PUERTAS}

Profesor doctor del Departamento de Periodismo de la Facultad de Ciencias de la Comunicación. Universidad Camilo José Cela

\section{María del Mar PERELLÓ ROSSELLÓ}

Profesora asociada de la Facultad de Ciencias de la Comunicación e Unidad Técnica de Departamento de Ordenación Académica. Universidad Camilo José Cela 